\title{
Study on the Selection of Hydrothermal Parameters of Frozen Layer
}

\author{
Liqing Liang ${ }^{1, a^{*}}$ \\ ${ }^{1}$ Jilin agriculture science and technology university, Jilin, Jilin, China \\ ahhs_liangliqing@126.com
}

Keywords: Permafrost; Groundwater; Hydrothermal; Hydrothermal parameters

\begin{abstract}
The formation of the frozen layer is related to many factors, but the most important one is the negative accumulated temperature of the surface. By analyzing the frozen layer research significance and frozen layer, frozen layer in the domestic and foreign development present situation and trend, compared to normal hydrothermal parameters of frozen layer, finally choose the moisture content, density and proportion of soil particles as a direct indicator; Based on the indirect index, the index is used as the indirect index, and the temperature and other environmental factors are combined to lay a foundation for the study of hydrothermal change and coupling analysis of permafrost.
\end{abstract}

\section{Introduction}

The frozen layer is the frozen soil layer. The formation of the frozen layer is related to many factors, but the most important one is the negative accumulated temperature of the surface. In winter, as the temperature drops, the surface temperature gradually decreases, and the temperature gradient is gradually propagated downward, causing the soil temperature to decrease gradually from top to bottom. When the temperature of a certain depth of the soil decreases to the freezing temperature of the deep soil (mainly related to moisture content and salinity), the soil begins to freeze. In the northern part of our country, the soil is easily formed by seasonal cold climate. The thickness of the frozen layer increases with the increase of the temperature, until the spring temperature rises, the permafrost begins to thaw, forming a special layer of soil melt, and its existence changes the law of the change of the groundwater level.

\section{The Meaning of Hydrothermal Parameters of Frozen Layer is studied}

To spatial and temporal distribution of water resources, the crop water requirement, the dislocation of rainfall and implementation of water saving food action under the background of the frozen layer hydrothermal mechanism and frozen layer vertical change has great significance in theory and production practice:

Layer of soil water research as permafrost thermal parameters monitoring properties and soil moisture, heat and salt, the basis of the determination of research can be applied to the amount of snow melt infiltration calculation, such as snowmelt runoff calculation, snowmelt flood forecast provides the basis;

In the process of freezing and thawing soil water infiltration, storage and frozen layer through the law of the permafrost research for wintering period permafrost water holding capacity (permafrost soil conservaton), wintering period surface water diving to recharge, spring snow melt period canals/provides the reference for the calculation of irrigation infiltration recharge, etc;

It is helpful to make full use of frozen soil water storage and moisture conservation, and can effectively and rationally utilize the limited soil water resources. To provide the basis for the reasonable determination of irrigation technology parameters in the cold region (the single width flow of irrigation under freeze-thaw or winter irrigation conditions, the size of the furrow field, the time of releasing water, etc.), and the evaluation of irrigation effect;

Study the change law of soil moisture in the process of freezing and thawing for spring planting soil moisture in the judgment, the phenomenon of "spring waterlogging" prevention and control, the 
accumulation of soil moisture information, and cold water conservancy, water and soil, luqiao, garden and so on provides the basis for the construction of infrastructure.

In seasonal frozen soil in cold regions, the hydrological cycle under the condition of low temperature and freezing and thawing process and the mechanism is not cold and more complex, applies theory and method of cold and cold water cycle research has a lot of problems, one of the outstanding problem is the existence condition of the frozen layer under the change of soil moisture.

\section{Domestic and International Development Status and Trend}

Domestic Research Status. In recent years, the research on the hydrophilic properties of the frozen layer has been focused on the numerical simulation of parameter determination method, water flow and solute migration, and the process of infiltration is determined by the water distribution state. Frozen layer of liquid water infiltration, mainly describes the vadose water temperature conditions is macro and micro regularity of occurrence and distribution, migration, for negative temperature conditions in permafrost, snow melt water infiltration belt involves few. In frozen soil science, mainly describes the permafrost itself, hot water and salt migration regularity of occurrence of, and permafrost engineering mechanical properties, fewer permafrost as special research of porous media.

The study on the hydrothermal monitoring of the frozen soil started late in the 1960s. Under the condition of permafrost, the influence factors of water infiltration and movement in unsaturated frozen soil are more complex, and the effect of temperature potential difference in soil is not negligible. In China, the research on the hydrothermal parameters of seasonal frozen soil has been widely carried out, and some achievements have been made. Cold and arid regions environmental and engineering research institute, Chinese academy of sciences since the $1970 \mathrm{~s}$, the freezing conditions affecting soil moisture migration, soil frost heave and salt expansion problems such as a large number of indoor experiment study[1,2], zhang through the wild field test study found that the soil water potential is a driving force of the water migration under the action of freezing and thawing[3]. By contrast experiment, zheng dongmei studied the temperature gradient of the soil in the frozen period of the salt marsh wetland and drove the soil water salt migration[4].

Research Status Abroad. Stoeckler and Weitzman started in 1960 to carry on the research on frozen soil infiltration[5], Bloomsbury and Wang were determined by indoor experiment in 1969, the moisture content of different freezing soil permeability[6], Kane et al., using the double loop test to determine the seasonal frozen soil infiltration of Alaska[7], Pikul and Wilkins for cultivation of frozen soil in different depth is different moisture content change monitoring research[8,9], 1980 Perfectand Wil lians first proves that the negative temperature gradient under the condition of temperature could induce liquid water sports[10], Oliphant is obtained by indoor test for different texture soils under the effect of temperature gradient of moisture migration[11]. The existing researches on hydrothermal parameters of permafrost mainly focus on : Study on the law of soil water heat migration, Research on the process of freeze-thaw soil water heat transfer. However, there are few researches on the method of water thermal parameter monitoring, and the existing non-freezing soil water thermal monitoring technology is usually used for research.

Overall, to search the literature more concentrated in the frozen soil infiltration, evaporation, runoff coefficient and frozen layer, elimination primarily for permafrost itself changes and moisture and heat transfer law were studied. Permafrost is regarded as a special kind of low-temperature ice body of porous media to study is less, in the heart of the frozen layer water rational qualitative frozen layer water-holding properties separately proposed research is rare and common types of test too little, fewer traditional monitoring technology, monitoring parameters, boundary conditions, lack of control affects the results and conclusion the representative and universality; It is very rare to study the influence factors and mechanism of permafrost water retention. 


\section{Selection of Hydrothermal Parameters of Frozen Layer}

The soil is a deposit of loose particles, composed of pores between solid particles and particles, and there is usually water and air in the pores, which is a mixture of solid particles, water and air. The particles in the soil are called solid phases, and the water in the soil is called the liquid phase, and the air in the pores is called the gas phase. The interconnection between soil particles and particles or the skeleton of the soil. When all the porosity of the skeleton is filled by water, referred to as the saturated soil, when the porosity of the skeleton only contains air called dry soil, generally within a certain depth below the ground water level above the ground of soil pore air and water, and included in the soil of the three-phase system, referred to as the wet earth.

The water in the soil type and amount have significant influence on the status and nature of the soil, soil water in addition to the part of the adsorbed on the solids in the form of crystallization water tight lattice inside, there is absorbed water and free water two kinds big. Mainly by physical and chemical forces absorbed water, free water is consists of a capillary water and gravity, capillary water surface tension and gravity, gravity water mainly by gravity. The volume of pore volume in soil is an important factor affecting the capacity of water storage capacity, and the porosity of pore volume is indicated by porosity. Porosity refers to the proportion of pore volume in a certain volume of soil. The size of porosity depends on the degree of separation and the arrangement of particles, and the shape of the particles and the filling of cementation also affect the porosity. For cohesive soil, structure and secondary porosity are important factors for porosity.

Water/Frozen Soil Thermal Physical Parameters Selection: mainly depends on the soil physical properties of the solid particle and pore water and gas volume and quality of these three accounts for the proportion, the physical properties of soil not only describe the physical properties of soil and it's status, and to some extent reflect the mechanical properties of soil. Part of the physical properties of soil must be determined experimentally, such as water content, density and the proportion of soil particles, i.e. direct indicators. The other part is based on direct index conversion, namely indirect index. The size, number, connectivity and evenness of the soil pore size have an effect on their storage capacity, retention, release and ability to penetrate water. It is very important to select appropriate parameters for monitoring and analysis during different periods of soil freezing.

Frozen Soil Layer/Hot Water Monitoring Technology Research and the Coupling Analysis: hydrothermal parameters monitoring is very important to this study, based on the condition of limited choice of the most ideal way of monitoring and monitoring instrument, based on the monitoring data of soil water heat coupling analysis method, is an important content of hydrothermal parameters of coupling.

The rock and soil temperature below the initial freezing temperature is called permafrost, and seasonal permafrost can be considered as a special connected system containing ice crystals. Permafrost is anisotropic porous media composed of rock particles, unfrozen water, air and ice, and the unfrozen water and ice in the frozen soil are very sensitive to temperature. Permafrost is seasonal frozen soil, the majority of seasonal frozen soil belongs to the unsaturated soil, it is generally believed by the permafrost soil particles, the pure ice four phase composition, pore water, air, soil particles and ice to form the basic skeleton of soil. The permafrost is not only the important property of soil, but also different from the non-permafrost. The mechanical properties of permafrost are not stable compared with that of non-permafrost. As the permafrost of the four-phase system, it has obvious rheological properties. The properties of conventional soil are mainly affected by the mineral and mechanical composition, density and water content of soil particles. The characteristics of frozen soil in addition to the related to the above factors, also affected by the amount of ice, the ice content directly related to the temperature, the decrease of temperature rise will cause ice content, low temperature, ice content. 
Table1 Soil water contents of Hulan experimental field

\begin{tabular}{lcccccc}
\hline \multicolumn{1}{c}{ Date } & 0cm depth & 20cm depth & 40cm depth & 60cm depth & 80cm depth & 100cm depth \\
\hline 2015.10 .20 & 0.22 & 0.241 & 0.246 & 0.254 & 0.219 & 0.225 \\
2015.10 .30 & 0.272 & 0.264 & 0.254 & 0.236 & 0.22 & 0.218 \\
2015.11 .6 & 0.231 & 0.255 & 0.253 & 0.238 & 0.224 & 0.217 \\
2015.11 .13 & 0.234 & 0.24 & 0.252 & 0.236 & 0.23 & 0.22 \\
2015.11 .20 & 0.254 & 0.23 & 0.252 & 0.237 & 0.224 & 0.213 \\
2015.11 .27 & 0.24 & 0.225 & 0.254 & 0.243 & 0.235 & 0.221 \\
2015.12 .4 & 0.247 & 0.247 & 0.251 & 0.238 & 0.233 & 0.22 \\
2015.12 .11 & 0.247 & 0.246 & 0.248 & 0.245 & 0.233 & 0.23 \\
2015.12 .18 & 0.251 & 0.245 & 0.248 & 0.243 & 0.24 & 0.229 \\
2015.12 .25 & 0.25 & 0.247 & 0.248 & 0.248 & 0.248 & 0.231 \\
2016.1 .1 & 0.252 & 0.249 & 0.25 & 0.249 & 0.25 & 0.245 \\
\hline
\end{tabular}

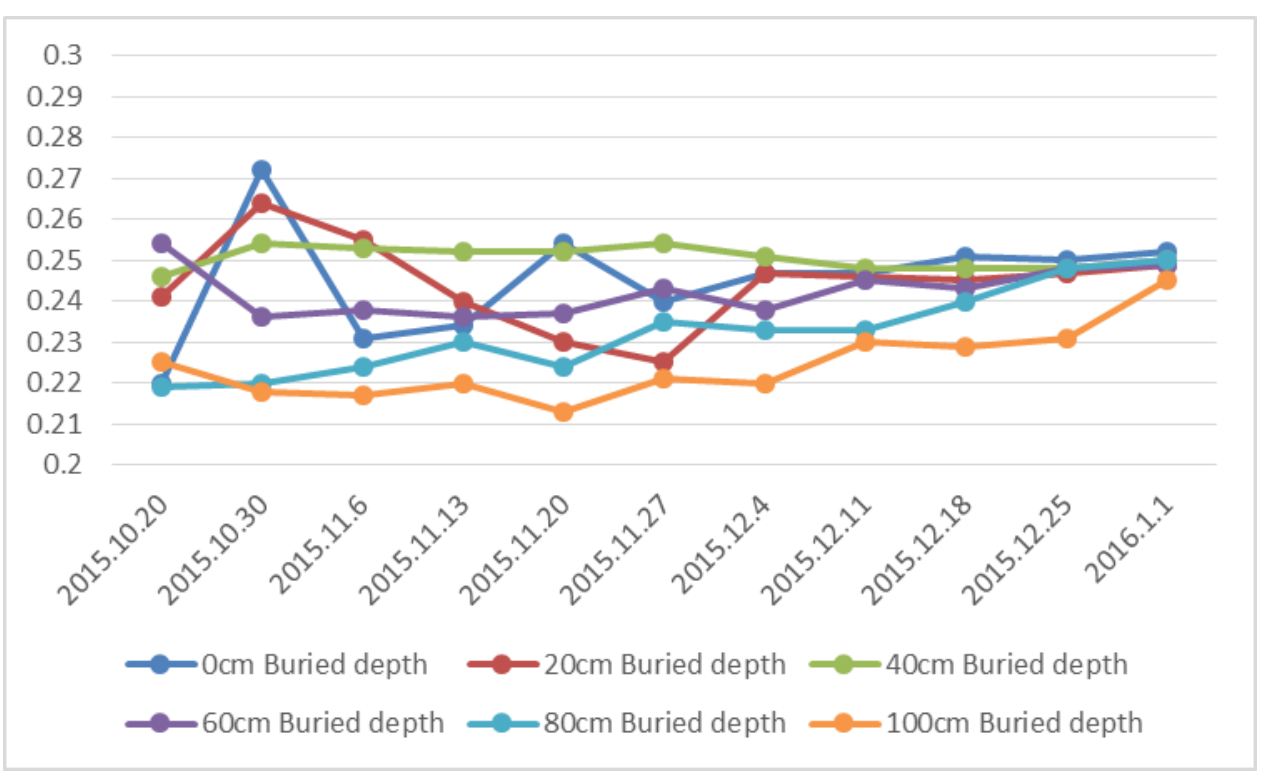

Figure 1. Change of soil water contents in different depths with time in Hulan experimental field

The above figure shows that the moisture monitoring data of the frozen period of the experimental plant above shows that the soil moisture content of $0-20 \mathrm{~cm}$ on the surface of the surface is affected by external conditions and has a great change before the stable freezing. It is affected by precipitation infiltration and surface evaporation, and the moisture content in the $20-40 \mathrm{~cm}$ soil layer before freezing is the largest. After November 20, the test field formed a stable layer of frozen soil, and the water was transferred to the frozen soil layer, and the soil moisture content in the frozen layer continued to increase.

\section{Summary}

Frozen water parameters of research can be frozen layer water provides the reference for the change and analysis of thermal parameters, which affect the frozen layer relevant calculations, such as calculation of snowmelt runoff, snowmelt flood forecasting, wintering period surface water diving to recharge and spring snow melt period canals/irrigation infiltration recharge of calculation; At the same time, it provides reasonable parameter selection for the irrigation area related technology, such as the reasonable determination of the technical parameters of irrigation water in the cold region, the evaluation of irrigation effect, and the judgment of soil moisture in spring till.

The research on the hydrothermal monitoring of the frozen soil in China started late in the 1960s, and the research on the hydrothermal parameters of the seasonal frozen soil has been widely carried out, and some achievements have been made. Abroad on permafrost research focused on the frozen soil 
infiltration, evaporation, runoff coefficient and frozen layer aspect, mainly for permafrost itself changes and moisture and heat transfer law, permafrost is regarded as a special kind of low-temperature ice body of porous media to study less.

Mainly depends on the soil physical properties of the solid particle and pore water and gas volume and quality of these three accounts for the proportion, the physical properties of soil not only describe the physical properties of soil and it's status, and to some extent reflect the mechanical properties of soil. Part of the physical properties of soil must be determined experimentally, such as water content, density and the proportion of soil particles, i.e. direct indicators. The other part is based on direct index conversion, namely indirect index. At the same time, the temperature and ice rate are used as the hydrothermal parameters of permafrost.

\section{Acknowledgements}

Jilin agriculture science and technology university school-level youth fund project: " Application of GMS based numerical simulation in groundwater resource evaluation " (no. : 213, 2017)

\section{References}

[1] X.Z. Xu, J.C. Wang, and L.X. Zhang, et: The mechanism of soil frost heave and salt expansion (Science press, China 1995). (In Chinese)

[2] Chen and Wang: Some Characters Clay During Freezing. of Ground Freezing, Vol. 11 (1985) No.4, p.63.

[3] L.X. Zhang, W.Y. Han, T.X. Gu: The effects of freezing and thawing process on soil water salt dynamics in the grass - pit basin of Glacial Permafrost, Vol. 23 (2003) No.3, p.297. (In Chinese)

[4] Z.D. Lei, S.H. Shang, S.X. Yang: Numerical simulation of soil water heat transfer in winter under shallow groundwater of Glacial Permafrost, Vol. 20 (1998) No.1, p.51. (In Chinese)

[5] Stoeckeler JH, and Weitzmen S: Infiltration rates in frozen soil in Northern Minnesota of Soil Sci.Soc.Am.J, Vol. 24 No.2, p.137.

[6] Bloomsburg GL,Wang SJ: Effect of moisture content on permeabilitu of frozen soil. Proc,16th Ann.Mtg, Pacific Northwest Region, American Geophysical Union, Washington DC.

[7] Kane DL, Stein J: Water movement into seasonally frozen soils of Water Resource. Res, Vol19, No.6, p.1547.

[8] [Pikul JL.Zuzel JF and Wilkins DE: Water infiltration into frozen soil: field measurements and simulation. In: Proc,Nat. Symp, Dec, p.16.

[9] Pikul JL.Zuzel JF and Wilkins DE: Infiltration into frozen soil as affected by ripping, Trans.ASAE, Vol.35, No.1, p.83.

[10]Perfect and Williams: Thermally induced water migration in frozen soil[J].Cold Reg.Sci.Techn. Vol.3, (1980), p.101.

[11] Oliphant and Nakano: Measurement of water migration due to a temperature gradient in frozen soil[J].Permafrost:Fourth International Conference Proceedings.National Academy Press, Washington D.C.USA, (1983), p.951. 